\title{
Globalização e desglobalização: outro dilema da Pós-Modernidade
}

\section{Globalization and deglobalization: another dilemma of Post-Modernity}

\author{
Patricio Dugnani \\ Universidade Presbiteriana Mackenzie \\ <patricio@mackenzie.br>
}

\begin{abstract}
Como citar este artigo (How to cite this article):
DUGNANI, Patricio. Globalização e desglobalização: outro dilema da Pós-Modernidade (Globalization and deglobalization: another dilemma of Post-Modernity). Revista Famecos, Porto Alegre, v. 25, n. 2, p. 1-14, maio, junho, julho e agosto de 2018: ID27918. DOI: http://dx.doi.org/10.15448/1980-3729.2018.2.27918.
\end{abstract}

\section{RESUMO}

Este artigo investiga o movimento paradoxal e desglobalizante de protecionismo, de neonacionalismo, e de fechamento de fronteiras da política das nações, em relação ao movimento contrário dos meios de comunicação digitais, internet, que tendem a pressionar as populações para ampliação dos contatos, cada vez mais globalizantes, dada ao alto potencial de alcance e extensão da percepção que esses meios são capazes de produzir nas relações humanas. Com isso, pretende-se analisar e compreender esse impasse que amplia as incertezas na sociedade, além de revelar a influência dos meios digitais no processo de globalização, e sua influência na constituição do sujeito pós-moderno. Compreender as tensões causadas pelo dilema entre intenções políticas nacionalistas e o movimento dos meios de comunicação globalizantes trará mais um componente, que revelará motivações para o aumento dos discursos nacionalistas, da xenofobia, e da intolerância quanto outras culturas, ideias, crenças. A pesquisa é teórica e exploratória, onde foi feito um levantamento bibliográfico e a observação dos fenômenos. Como se trata de uma pesquisa teórica, tem-se como resultado a produção de um texto que possa fornecer subsídios para compreensão de um fenômeno dos nossos dias, bem como a produção de um material que possa dar acesso às teorias da comunicação e da organização política a outros pesquisadores.

Palavras-chave: Comunicação. Globalização. Desglobalização.

\section{ABSTRACT}

This article will investigate the paradoxical and deglobalizing movement of protectionism, of neonationalism, and the closure of nation's politics frontiers, in relation to the opposite movement of the digital media, Internet, that tends to press the populations for the expansion of the contacts, increasingly globalizing, given the high potential of reach and extension of the perception that these means are able to produce in human relations. The aim is to analyze and understand this impasse that amplifies the uncertainties in society, in addition to revealing the influence of digital media in the process of globalization, and its influence on the constitution of the postmodern subject. Understanding the tensions caused by the dilemma between nationalist political intentions and the globalizing media movement will bring one more component, which will reveal motivations for increasing nationalist discourses, xenophobia, and intolerance as other cultures, ideas, and beliefs. The research is theoretical and exploratory, where a bibliographical survey and the observation of the phenomena. As a theoretical research, is expected the production of a text as result, that can provides subsidies to understanding a phenomenon of our times, as well as the production of a material that could provide access to the theories of communication and political organization to other researchers.

Keywords: Communication. Globalization. Deglobalization. 


\section{Introdução}

Notícias que deixaram perplexos os espectadores e a comunidade mundial no ano de 2016, como a saída da Inglaterra do Mercado Comum Europeu e a Eleição de Donald Trump com sua visão protecionista e crítica à globalização, parecem contraditórias em relação às tendências globalizantes das relações sociais e políticas que os meios digitais imprimem na sociedade.

Por causa desses indícios protecionistas e de fechamento das fronteiras, que têm sido apresentados, mais frequentemente, pelas propostas políticas das nações, este artigo investiga o movimento paradoxal dessas políticas, em relação ao movimento contrário dos meios de comunicação digital e a internet, que tendem a pressionar as populações para ampliação dos contatos, cada vez mais globalizados, dado ao alto potencial de alcance e extensão da percepção que esses meios são capazes de produzir nas relações humanas. Por causa dessa questão, parece surgir uma pergunta: será possível que o aparente movimento contrário à globalização, ou desglobalizante, poderá resistir à pressão globalizante dos meios de comunicação?

Para analisar esse fenômeno de contradição entre os meios de comunicação e a política externa, parte-se da visão entre sociedade e mídia de Marshall Mcluhan (1996), com suas teorias sobre alcance e extensão dos meios, e a sociedade. Além de Mcluhan (1996), buscou-se compreender sobre a pós-modernidade, globalização e sujeito pós-moderno, através das ideias de Stuart Hall (2004); sobre incerteza, liquidez, e interregno, pelos pensamentos de Zygmunt Bauman (2008); o entendimento sobre a mundialização, desterritorializacão e não-lugar a partir dos conceitos de Marc Augé (2004) e dos debates de Renato Ortiz (2000).

A verificação do descontentamento da população mundial em relação à globalização é analisada pela visão crítica de Milton Santos (2007). Essa insatisfação tem sido considerada um dos motivos para a vitória de Trump nos Estados Unidos da América e, provavelmente, pode estar pressionando algumas decisões dos eleitores da França. Essa insatisfação com a globalização das doenças, da pobreza, e da centralização das riquezas cada vez maior, pode ser a mola propulsora para um resgate do pensamento xenofóbico no mundo, que se alimenta do ódio e que tem se potencializado por causa das grandes imigrações de povos que fogem da miséria, da fome e das guerras.

Essas tensões sociais e políticas direcionam essas relações para um processo que, neste artigo, denominou-se de desglobalização. Esse termo é designado para denominar tendências que surgiram contrárias ao processo de globalização, que são percebidas cada vez mais nos discursos políticos da pósmodernidade. 
Com esta reflexão, apresenta-se o movimento complexo e paradoxal de desglobalização dos sistemas políticos e de globalização dos meios de comunicação, para buscar compreender esse impasse que amplia as incertezas e as tensões entre os grupos humanos da sociedade em âmbito mundial.

\section{Globalização e Desglobalização}

Mas, o que é globalização? Dos diversos conceitos de globalização, neste texto preferiu-se o de Stuart Hall (2004), no qual o autor fala de um processo mundial de contatos e de conectividade, que ultrapassam os limites das nações, transformando pelas trocas de informações entre culturas diferentes, o comportamento e a consciência do sujeito.

[...] a "globalização" se refere àqueles processos, atuantes numa escala global, que atravessam fronteiras nacionais, integrando e conectando comunidades e organizações em novas combinações de espaço-tempo, tornando o mundo, em realidade e em experiência mais interconectado (Hall, 2004, p. 67).

A globalização somente se concretiza, pois é sustentada pela dinâmica mundial de trocas de informações entre culturas distintas, que se torna possível graças ao desenvolvimento de tecnologias que ampliaram e estenderam o alcance dos meios de comunicação.

Com esse processo de trocas de informações, a consciência do humano em sociedade se modifica. Quanto maior a quantidade de informações, e quanto mais rápida for a troca dessas informações, maiores e mais rápidas serão as mudanças. Quanto mais rápidas essas mudanças forem, mais instáveis serão as certezas e, com isso, maior a sensação de incerteza perante tantos modelos e conceitos novos que surgem constantemente. Ou seja, dentro desse processo, como pode-se perceber, surge o sujeito da sociedade da incerteza, fragmentado e com valores cambiáveis: o sujeito pós-moderno. Dessa forma, com a globalização produzida pelos meios de comunicação elétricos e digitais, se constitui uma identidade pós-moderna.

Logo, a revolução dos meios digitais, o sujeito da pós-modernidade e a globalização são fenômenos que não são independentes, pelo contrário, estão intimamente relacionados, e, de certa forma, um influencia o outro. Contudo, não existiria a globalização, nas dimensões que se conhece hoje, nem, consequentemente, se constituiria o sujeito, que Hall (2004) denomina como pós-moderno, se não houvesse a possibilidade de trocas eficientes e intensas entre os indivíduos de culturas e nações distintas, ou seja, não existiria pós- 
modernidade, nem tampoucoaglobalização, senãohouvesseo desenvolvimento dos meios de comunicação, principalmente os digitais, e a internet.

Se a globalização é esse fenômeno de mistura de culturas - que Roland Barthes (2004) denomina como intertextualidade - que se torna possível através dos meios de comunicação com alcance mundial, então o que é a desglobalização?

A desglobalização é um termo que está sendo utilizado nesse texto para identificar algumas tendências e ideias que estão povoando o imaginário de alguns grupos humanos, além de atitudes que estão sendo tomadas por instituições, ou enunciadas em discursos por representantes políticos de algumas nações. Pode-se notar essa tendência de fechamento de fronteiras culturais, sociais e econômicas no discurso do recém-eleito presidente dos Estados Unidos da América, ou na decisão, em plebiscito, da população do Reino Unido em deixar o Mercado Comum Europeu. Também é possível perceber essas tendências desglobalizantes no crescente sentimento de xenofobia nos países europeus, ou na limitação das fronteiras ideológicas do Estado Islâmico. Essas ideias de protecionismo, políticas contra as imigrações, fechamento de fronteiras físicas ou ideológicas, todos esses movimentos são sintomas de uma crescente desconfiança das estratégias globalizantes do mercado, contudo, vão em direção contrária ao movimento de aumento de contatos globais impressos pelos meios de comunicação digitais e a internet.

Tabela 1. Globalização e Desglobalização

\begin{tabular}{|l|l|}
\hline \multicolumn{1}{|c|}{ Globalização } & \multicolumn{1}{|c|}{ Desglobalização } \\
\hline $\begin{array}{l}\text { Meios de Comunicação } \\
\text { Globalizantes }\end{array}$ & Nações e economias protecionistas \\
\hline Fragmentação pós-moderna & $\begin{array}{l}\text { Repolarização das Culturas e } \\
\text { Ideologias }\end{array}$ \\
\hline
\end{tabular}

Fonte: $\mathrm{O}$ autor

No decorrer do texto, amplia-se a reflexão do seguinte debate: como está se apresentando esse paradoxo, e o impasse que ele cria, ou seja, como tendências desglobalizantes da política de algumas nações e grupos sociais vão resistir à pressão globalizante dos meios de comunicação digitais e a internet? Se houver resistência, como as instituições deverão desenvolver maneiras técnicas e legais para coibir a globalização, consequência inevitável do uso dos meios digitais?

Claro que não se pretende ter a resposta para um problema tão complexo, mas ampliar o debate e a consciência sobre esse assunto, e, principalmente, 
entender a relação entre meios de comunicação, pós-modernidade e globalização, para poder concluir que existe essa situação contraditória entre a vontade (tendência) globalizante dos meios de comunicação digitais e a vontade protecionista de alguns grupos humanos e instituições políticas.

\section{Meios de Comunicação e Organização Política}

Considera-se nesse artigo, a partir das ideias de McLuhan (1996), que os meios de comunicação, a partir da invenção dos meios elétricos e dos meios de comunicação de massa, tendem a constituir uma aldeia global entre os grupos humanos disseminados pelo mundo. Segundo McLuhan (1996) os meios de comunicação são tribalizantes. Porém, antes de entender essas questões, é preciso destacar três ideias consideradas fundamentais na teoria de Mcluhan (1996) para compreender a influência dos meios de comunicação na organização política do ser humano. São elas:

1) Meios como extensões do humano;

2) Meio é a mensagem;

3) Aldeia Global;

Uma das ideias fundamentais de McLuhan já se identifica no título de um dos seus principais livros: Os Meios de Comunicação como Extensões do Homem (1996). O conceito de extensão é central na teoria dos meios, pois rompe com uma visão tradicional de que os meios de comunicação eram meros transmissores de informação, ou simples canais, que faziam a ponte entre emissores e receptores. Os meios de comunicação não são apenas meios responsáveis pela transmissão das informações, mas, para McLuhan (1996), são extensões do humano. Mas o que significa isso? Significa que os meios de comunicação como extensões do humano fazem com que os sentidos humanos sejam ampliados e, com eles, a percepção humana do mundo. Com a televisão, por exemplo, sou capaz de ver além do limite dos meus olhos, com o rádio posso escutar além do alcance dos meus ouvidos. Ou seja, com os meios de comunicação os meus sentidos se estendem pelo mundo, e sou capaz de receber muito mais informações, e muito mais influências de outras culturas, que, de certo modo, caracteriza o fenômeno da globalização que os meios de comunicação são capazes de promover.

Entendendo informação não somente como um conteúdo de uma mensagem, mas um conteúdo capaz de produzir mudança no comportamento e na consciência do receptor (Netto, 1990), pode-se concluir que quanto mais informação um receptor recebe, e quanto mais variada ela for, maiores e mais rápidas serão as mudanças que serão percebidas nas sociedades e nas culturas humanas. Por isso, os meios de comunicação, mais do que meros transmissores, promovem a extensão da percepção humana, e, por conseguinte, promovem 
mudanças profundas nas organizações sociais humanas, inclusive (o que interessa muito para essa pesquisa) na organização política humana. Por causa dessas questões é que McLuhan (1996) define os meios de comunicação como extensões humanas.

A segunda questão, talvez a frase mais conhecida de McLuhan (1996), "o meio é a mensagem", amplia esse debate sobre a influência dos meios de comunicação na vida humana, quando afirma que, mesmo independente das mensagens, os meios de comunicação promovem mudanças no comportamento e na consciência dos seres humanos e em suas organizações sociais. A simples invenção e uso dos meios alteram o comportamento humano, assim como as informações contidas nas mensagens. Por isso, mais do que meios transmissores de mensagens, como dito anteriormente, os meios de comunicação estendem a percepção humana, promovem mudanças nos seres humanos, então pode-se considerar que os meios de comunicação são informações puras, por isso que McLuhan (1996) afirma que o meio é a mensagem.

A terceira questão, a aldeia global, é uma consequência da extensão da percepção humana e das alterações que produzem no comportamento humano. A partir da invenção dos meios elétricos houve um aumento do contato entre as culturas, e essa ampliação produz um efeito de trocas de informações e, consequentemente, uma uniformização das culturas, fenômeno que o autor acredita que vai produzir a aldeia global. Termo que parece antagônico, pois se refere ao contato global de culturas, que se aproximam convivendo de maneira mais próxima, como as relações dos indivíduos que compõem uma pequena tribo. Por isso, para McLuhan (1996), os novos meios de comunicação elétricos, posteriormente, os meios de comunicação em massa, são retribalizantes. A partir dessa conclusão, pode-se estender esse fenômeno de retribalização através dos meios de comunicação digital. Um exemplo que se pode dar desse fenômeno nas novas mídias digitais são os sites de relacionamento, como o Facebook, Twitter etc., onde os indivíduos se juntam em comunidades por interesses comuns, e não somente por questões de proximidade espacial, legal ou nacional.

O alcance e extensão dos meios de comunicação modificam a consciência e o comportamento humano. Dessa forma, é que a organização política humana está intimamente relacionada ao alcance e à extensão dos meios de Comunicação. Percebe-se melhor isso ao ler McLuhan (1996), quando ele relaciona as grandes revoluções tecnológicas dos meios de comunicação, às transformações da organização política da história da humanidade.

Quando o humano apenas dispunha da fala, o alcance da fala, que é limitado espacialmente em relação a outros meios, influenciava a dimensão 
da organização política humana. O alcance da fala possibilita grupos humanos limitados, tanto na ocupação espacial, como na quantidade de integrantes: a fala está para tribo. A fala está para a tribo, pois esse meio de comunicação não tinha registro material, ou seja, as expressões culturais de um povo deveriam ficar registrados na memória, e deveriam ser passadas de geração para geração através da repetição dos ritos, das histórias. A fala é transmitida de pessoa para pessoa, voltada para a exteriorização, e não tem segredo, ela se constitui a partir do momento em que o emissor está transmitindo a mensagem para o receptor. Essa comunicação de pessoa para pessoa, prevê a necessidade da presença de seus interlocutores. A dimensão da tribo está relacionada ao alcance da fala.

No momento em que o ser humano desenvolve um registro eficiente de sua memória, de sua cultura, de sua fala, ou seja, através da escrita fonética, sua relação passa a ser burocrática, e as lideranças podem se separar dos liderados, pois a escrita os representa, mesmo quando estão ausentes, por isso burocráticas, a escrita pode representa-los, presentificá-los. Como a mensagem pode ser transportada sem a presença física do emissor, a informação pode atingir uma população maior, e ocupar também um espaço maior. Dessa forma, pela escrita, as comunidades ampliam a uniformização de culturas e diversas tribos se juntam, seja pela força, seja por interesses.

Então, se a fala está para tribo, a escrita está para as grandes civilizações. A escrita seria a extensão da fala, de acordo com McLuhan (1996). E se a escrita é a extensão da fala, também deverá estender a organização política humana. Ou seja, a escrita estende a tribo. Pode-se perceber isso, pois o desenvolvimento da escrita fonética coincide com o surgimento das grandes civilizações egípcia, mesopotâmica e clássica (Cidades-Estados Gregas, Macedônia e Roma).

Após a escrita, a invenção da reprodução da escrita, da prensa móvel e da tipografia, simbolizada por Gutenberg no final do século XV, fim da Idade Média e Início da Moderna, apenas ampliou esse fenômeno denominado por McLuhan (1996) de destribalização, pois, as comunidades cresciam e as relações pessoais ficavam diluídas nas grandes massas de uma população uniformizada, as quais chamamos de nações. O que justifica a nação é a proximidade espacial e cultural, as fronteiras e o sentimento de nacionalismo, o qual é preciso ser semeado constantemente naquela população heterogênea. A nação foi uma invenção que foi possível graças a meios de comunicação mais potentes e rápidos, capazes de uniformizar massas cada vez maiores em torno de um ideal. A nação está para a impressão, como a fala para tribo, e a escrita para as grandes civilizações.

Contudo, McLuhan (1996), diferente do pensamento da Escola de Frankfurt, acredita que com a revolução dos meios elétricos, e os meios de 
comunicação de massa, esse processo se reverteria, pois com a velocidade elétrica dos novos meios, e com a quantidade de informações que eles poderiam transmitir, um novo tipo de relacionamento nasceria, uma aldeia global, onde as culturas se aproximariam, como foi dito anteriormente, criando um novo espaço retribalizado, não de relações burocráticas como as impressas pela escrita, mas de participação e de aproximação por interesses.

Dessa reflexão, pode-se chegar aos meios de comunicação digital, que se constituem com o fortalecimento da possibilidade de os indivíduos emitirem suas mensagens de forma global, e mais independente, do que era feita por outros meios anteriores. Indivíduos que trocam informações globais, que se aproximam de outros grupos de interesse, acabam por criar novas comunidades, novas tribos. Conforme essas trocas continuarem, e se ampliarem, é possível chegar ao humano global, às culturas misturadas, híbridas e, também, globais: ou seja, a aldeia global. A globalização das culturas é apoiada pelos meios de comunicação elétricos, de massa e digitais. Como sinalizou Ortiz (2000, p. 140), de maneira crítica, "[...] a dimensão global supera o aspecto nacional".

Com essas reflexões, pode-se chegar à conclusão de que os meios de comunicação alteram comportamentos, consciências e a própria organização política humana, com isso, os meios de comunicação digitais são também responsáveis pela globalização. Essa tecnologia, com sua capacidade intensa de interação, de contato constante, de mobilidade, possibilita uma extensão global da percepção humana, possibilitando o surgimento de um humano global, em uma cultura global. Por isso, nesse artigo defende-se a ideia de que os meios de comunicação pressionam a população para um processo de globalização, e que é paradoxal, o movimento contrário que determinadas políticas protecionistas, e de fechamento de fronteiras, querem implantar e resgatar nesse momento contemporâneo. Esse movimento parece surgir na contramão do potencial dos meios de comunicação, e essa situação poderá criar uma pressão que poderá ampliar as tensões já existentes em nosso panorama social. A pergunta é: quem resistirá a esse embate, a tendência globalizante dos meios, ou a força burocrática das nações? Esse é um debate que se deve acompanhar com atenção. 
Tabela 2 - Meios de Comunicação e Organização Política em Marshall McLuhan

\begin{tabular}{|c|c|c|}
\hline Meios de Comunicação & Características & Organização Política \\
\hline Fala & $\begin{array}{l}\text { - Memória } \\
\text { - Exterior } \\
\text { - Tribalização } \\
\text {-Padronização/ } \\
\text { uniformização } \\
\end{array}$ & Tribo \\
\hline Escrita (fonética) & \begin{tabular}{|l} 
- Registro material \\
- Segredo \\
- Burocrático \\
- Destribalização \\
-Padronização/ \\
uniformização \\
\end{tabular} & $\begin{array}{l}\text { Grandes Civilizações Egito, } \\
\text { Mesopotâmia, e Clássica }\end{array}$ \\
\hline Meios Impressos & \begin{tabular}{|l} 
- Registro material \\
- Segredo \\
- Burocrático \\
- Destribalização \\
-Padronização/ \\
uniformização \\
- Mecanização \\
\end{tabular} & Nação/ nacionalismo \\
\hline Meios Elétricos & $\begin{array}{l}\text {-Padronização/ } \\
\text { uniformização } \\
\text { - Industrial } \\
\text { - Retribalização }\end{array}$ & $\begin{array}{l}\text { Internacionalização de } \\
\text { Culturas }\end{array}$ \\
\hline $\begin{array}{l}\text { Meios de Comunicação } \\
\text { de Massa }\end{array}$ & $\begin{array}{l}\text { - Receptor passivo } \\
\text {-Padronização/ } \\
\text { uniformização } \\
\text { - Industrial } \\
\text { - Retribalização }\end{array}$ & $\begin{array}{l}\text { Internacionalização de } \\
\text { Culturas } \\
\text { Massificação }\end{array}$ \\
\hline Meios Digitais/ internet & $\begin{array}{l}\text { - Interação } \\
\text { - Mobilidade } \\
\text { - Emissor e receptor } \\
\text { ativos } \\
\text { - Padronização/ } \\
\text { uniformização } \\
\text { - Retribalização }\end{array}$ & $\begin{array}{l}\text { Globalização } \\
\text { Informação }\end{array}$ \\
\hline
\end{tabular}

Pós-Modernidade: A Era da Incerteza, a Liquidez, o Interregno e o NãoLugar

Uma das grandes marcas da pós-modernidade é, com certeza, a incerteza. Porém, uma incerteza que autores consideram como uma mudança de paradigma, como Lyotard (2000), que vê a pós-modernidade como o "reconhecimento da heterogeneidade", assim como observa que o "consenso 
se tornou valor ultrapassado" (Lyotard, 2000, p. 118). Essa incerteza acaba por gerar a necessidade do desenvolvimento de novas metanarrativas (discursos que influenciam a consciência de uma sociedade - família, moral, lei, política, religião, etc.), ou seja, novas leis, novas ciências, novas verdades, que vagueiam incertas nos jogos de linguagens. "Nesta disseminação dos jogos de linguagem, é o próprio sujeito social que parece dissolver-se" (Lyotard, 2000, p. 73).

Porém, essas incertezas acabam por afetar a identidade cultural na pósmodernidade, como disse Lyotard (2000) referindo-se à dissolução do sujeito social. Essa dissolução, essa incerteza, pode ser observada na investigação de Hall (2004), quando o pesquisador dos Estudos Culturais vê no sujeito pós-moderno tanto a incerteza como o potencial de adaptação desse sujeito, qualificando-o como sendo uma "celebração móvel" (Hall, 204, p. 13). As fronteiras desse sujeito social se confundem, ele se torna mais fragmentado, pois ao receber informações rápidas, de diversas culturas diferentes, suas verdades se tornam menos sólidas, suas certezas mais fragmentadas e as fronteiras das metanarrativas se tornam menos definidas. Essas características emergem, também, da tendência globalizante dos meios.

Ou seja, o mundo do sujeito pós-moderno se torna mais volátil, e segundo Bauman (2008), mais líquido. Essa falta de solidez da identidade, do sujeito e da sociedade pós-moderna, é denominada por Bauman (2008) por liquidez: a liquidez da sociedade pós-moderna.

Bauman (2008) afirma que, a modernidade líquida, ou como denominamos de maneira mais comum, a pós-modernidade, vive um interregno, "“...] um espaço e um tempo estendidos, móveis, imateriais, sobre os quais reina o princípio da heterogenia de fins, talvez como nunca antes" (Bauman e Mauro, 2016, p. 09).

O interregno de Bauman parece muito com o que Augé (2004) conceituou como não-lugar e Ortiz (2000), em concordância com Augé, definiu como um espaço desterritorializado que, devido à eliminação das particularidades, e a colagem de diversos elementos, das mais variadas culturas, acaba por ser capaz de abrigar qualquer indivíduo.

Contrariamente aos "lugares", carregados de significado relacional e identitário, o espaço desterritorializado "se esvazia" de seus significados particulares. [...] parecem constituir uma espécie de"nãolugar", locais anônimos, serializados, capazes de acolher qualquer transeunte, independentemente de sua idiossincrasia (Ortiz, 2000, p. $105-106)$.

Esse movimento de mistura e homogeneização de culturas mundiais, e a incerteza provocada por ele é, certamente, pressionado pela rapidez dos meios de comunicação digital, que sustentam a globalização, pois os meios 
potencializam a mistura de culturas e as trocas de informação, como foi dito anteriormente, por isso, que esse sujeito precisa constantemente rever suas certezas e adaptar-se, pois a cada momento novas ideias e conceitos, novas informações modificam sua consciência de mundo e seu comportamento, modifica seus valores e sua cultura. O sujeito da pós-modernidade vive o interregno, pois parece estar em uma transição constante, como disse Bauman (2016), entre algo que já foi, e algo que virá. Por isso, torna-se estranho, que os movimentos políticos queiram deter esse movimento.

O sujeito pós-moderno, o interregno, e o não-lugar são sintomas que demonstram como a globalização, sustentada pelos meios de comunicação digitais, tem modificado profundamente o comportamento e a consciência do humano contemporâneo, através de seu potencial de troca de informações, por isso parece contraditório as tendências políticas de fechamento de fronteiras, culturas e economias.

Parece que esse movimento contrário entre a pressão globalizante dos meios, e as políticas restritivas e desglobalizantes, deverão ampliar mais a sensação de incerteza, que já é uma marca do sujeito e da sociedade pósmoderna. Os discursos de alguns grupos políticos têm a pretensão de querer conter, de maneira artificial e burocrática, a liquidez da pós-modernidade e seu alto potencial de adaptação. Quem deverá vencer essa queda de braço? Isso, se houver vencedores, pois com toda essa tensão, talvez apenas aumente a incerteza e as contradições se tornem insustentáveis.

\section{Considerações Finais}

A globalização é uma tendência de mistura de culturas, que é possibilitada graças, primeiramente, ao alcance dos meios de comunicação elétricos e de massa, e potencializada pelo poder de trocas de informações dos meios de comunicação digital. Ocorre e também está relacionada à pós-modernidade, e ao sujeito pós-moderno.

Esse conjunto de fenômenos produziu alguns efeitos como:

1) Formação de identidades menos centralizadas, mais fragmentadas e com alto potencial de adaptação, de acordo com Hall (2004);

2) As instituições, os discursos formadores do social (metanarrativas), as relações e a moral se tornam mais líquidas, de acordo com Bauman (2008);

3) Essa liquidez e incerteza levou a um nomadismo, tanto físico (deslocamento físico de indivíduos no espaço) como um nomadismo ideológico (ideais que se modificam com rapidez); 
4) Os indivíduos estão mais hedonistas, e observa-se uma supervalorização da aparência em detrimento da essência;

5) O sujeito desse período demonstra uma grande autonomia, porém, o individualismo se torna crescente;

6) A sensação de incerteza é crescente, devido, também, à velocidade de trocas de informação dos meios digitais de comunicação.

Dessas características que se encontram no humano pós-moderno e globalizado, alguns autores destacam elementos positivos. Lipovetsky (2004) destaca a autonomia do sujeito pós-moderno ligado aos meios de comunicação digital, pois, diferente do sujeito dos meios de comunicação de massa, o primeiro é mais interativo, participativo, seus discursos são mais independentes, menos moldados pelas estratégias de massa, ou pelas metanarrativas; enquanto o segundo era mais passivo e conformado, massificado pelas informações que vinham pelos meios. Esse sujeito pós-moderno da globalização, por exemplo, é capaz de desenvolver uma ética inteligente, "que alterou os valores" (Cruz, 2013, p. 28). Já para Linda Hutcheon (1991), pode-se perceber no pensamento da autora que a pós-modernidade foi iniciada recentemente e que uma nova consciência mais preocupada, por exemplo, com a natureza e com a ecologia, deverá surgir, ou seja, a pós-modernidade nesse processo de globalização reconstituíra novos ideais, novas maneiras de pensar e interagir com o mundo. Ela é otimista em relação à contemporaneidade.

Porém, para Milton Santos (2007) a globalização é uma farsa, uma fábula, como sentenciou o próprio autor, pois apenas globaliza as perversidades como doenças, pobreza e miséria. Provavelmente é essa percepção que levou o eleitorado dos Estados Unidos a eleger as propostas de Donald Trump, que se apresentam de maneira protecionista onde, em sua campanha, pregava o fortalecimento interno das fronteiras. O mesmo sentimento de perda perante à globalização provavelmente levou o povo inglês, em um plebiscito, a votar pela saída do Reino Unido do Mercado Comum Europeu. Talvez, seja preciso, para tentar reverter esse movimento desglobalizante, buscar, como afirma Santos (2007), uma globalização mais justa, "engajada", onde os interesses do capital internacional não se sobreponham sobre os interesses sociais das populações, onde as culturas não sejam impostas artificialmente e se possa ter uma mistura de culturas mais equilibrada e justa.

Os meios de comunicação digitais já possibilitam a miscigenação de culturas, cabe ao humano, à política humana, buscar soluções para os impasses, e, certamente, não é com o movimento inverso à globalização que as políticas protecionistas e desglobalizantes vão conseguir solucionar esse impasse que 
vive a população mundial. Muito pelo contrário, esse movimento apenas deverá ampliar as tensões entre essas populações, reforçando as incertezas, e diminuindo a possibilidade das trocas de informação, dificultando o diálogo entre as culturas, o que pode levar à ampliação da incompreensão, da xenofobia, e da intolerância.

Torna-se necessário e urgente refletir sobre a questão da comunicação entre as diferentes sociedades, para que se impeça um aumento da violência e da incompreensão. Esse artigo se pretende a isso, não é capaz de apresentar todas as soluções, mas sugerir que não se interfira com o potencial globalizante dos meios, mas sim, com as políticas humanas desglobalizantes, pois essas, sim, parecem estar causando essa onda retrógrada de incompreensão entre os humanos, que vale lembrar, pertencem à mesma espécie.

\section{REFERÊNCIAS}

AUGÉ, Marc. Não Lugares: introdução a uma antropologia da supermodernidade. São Paulo: Papirus, 2004.

BARTHES, Roland. O Rumor da Língua. São Paulo: Martins Fontes, 2004.

BAUMAN, Zygmunt. Vida para Consumo. Rio de Janeiro: Zahar, 2008.

BAUMAN, Zygmunt; MAURO, Ezio. Babel: Entre a Incerteza e a Esperança. Rio de Janeiro: Zahar, 2016.

NETTO, José Teixeira Coelho. Semiótica, Informação e Comunicação. São Paulo: Perspectiva, 1990.

CRUZ, Daniel Nery da. Lypovetsky x Bauman. Revista Conhecimento Prático Filosofia. São Paulo: Escala, Ano 7, ed. 46, p. 18-35, dez. 2013.

HALL, Stuart. A Identidade Cultural na Pós-Modernidade. Rio de Janeiro: DP\&A, 2004.

HUTCHEON, Linda. A Poética do Pós-modernismo. Rio de Janeiro: Imago, 1991.

LYOTARD, Jean-François. A Condição Pós-Moderna. Rio de Janeiro: José Olympio, 2000.

LIPOVETSKY. Gilles. Os tempos Hipermodernos. São Paulo: Barcarolla, 2004.

MCLUHAN, Marshall. Os Meios de Comunicação como Extensões do Homem. São Paulo: Cultrix, 1996. 
ORTIZ, Renato. Mundialização e Cultura. São Paulo: Brasiliense, 2000.

SANTOS, Milton. Por uma outra Globalização: do pensamento único à consciência universal. Rio de Janeiro: Record, 2007.

Recebido em: 8/7/2017

Aprovado em: 27/9/2017

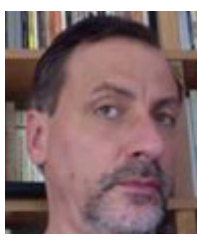

Dados do autor:

Patricio Dugnani - <patricio@mackenzie.br>

Universidade Presbiteriana Mackenzie

Doutor em Comunicação e Semiótica pela Pontifícia Universidade Católica de São Paulo. Professor de

Comunicação e Artes da Universidade Presbiteriana Mackenzie.

Endereço do autor:

Rua da Consolação, 930 - Consolação

01302-907 - São Paulo - SP - Brasil 